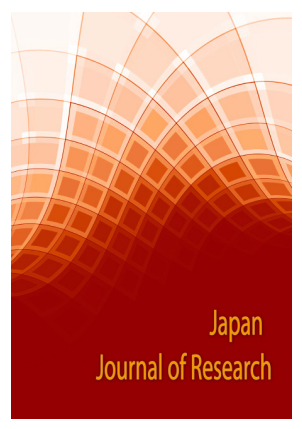

Correspondence

Fei Jiaming

Sports Institute of Huaibei Normal University , Huaibei Anhui 235000, China

E-mail: feijiaming@163.com
Keywords

Japan; Prevention of Aging; quality of life; successful experience; Enlightenment
Copyright

(c) 2021 Science Excel. This is an openaccess article distributed under the term of the Creative Commons Attribution 4.0 International license.

\title{
Successful experience and enlightenment in the prevention of aging and the construction of the Old- Age Service System in Japan
}

\author{
Fei Jia-ming and LiMeng-wei \\ Sports Institute of Huaibei Normal University, Huaibei Anhui 235000, China
}

\begin{abstract}
Using the methods of literature research, Comparative Analysis, etc. , this paper has discussed the historical process of aging and the similarities and differences between Japan and China. Under the background of the accelerating progress of the population ageing in our country and the increasing number of disabled and semi-disabled elderly, and with reference to the successful experience of Japan in the prevention of aging, this paper has introduced the concrete measures of preventing aging and the construction of advanced and Scientific Social Old-age Service System in Japan. In the light of the current situation of the population ageing in China, learning from the specific measures and successful experience of Japan in the prevention of aging, in order to extend the health years of the elderly in China for more than years and improve their quality of life, it provides the beneficial references for constructing the new social old-age service system.
\end{abstract}

\section{Introduction}

Japan entered the population ageing in the 1970s and was the first Asian country to enter the population ageing. At the end of 2019, Japan had a population of 126 million and a population of 35.94 million over the age of 65 , accounting for 28.5 percent of the total, according to the Statistics Bureau. Projected to reach 35.7\% by 2050. Japan has become a typical aging country with very few children. In response to the huge impact of the population ageing on social and economic development, the Japanese government has been actively constructing a social pension service system. From the end of the last century, our country has entered the population ageing stage. By the end of 2019, the population over the age of 65 of China has reached 176 million, accounting for 12.57 percent of the total population. By 2050, the proportion of the elderly population in China will reach over 30 percent. Although China and Japan have different national conditions, people's feelings and institution, they are separated by a narrow strip of water and respect for the elderly is one of the core values of the Eastern Asian countries. Therefore, we should learn from and refer to the successful experience of Japan in providing social services for the elderly, in particular, the advanced conception and scientific practice of "prevention of aging" and "exercise rehabilitation for the elderly" have great theoretical value and practical significance for our country's pension cause and how to deal with the population ageing.
Prevention of aging and successful construction of social pension service system in japanese experience

Aging is a normal physiological phenomenon. After birth, development, growth and maturity, the human body begins to decline in various body functions. At the same time, the human body in the ability to adapt to the environment and external pressure will gradually weaken, physiological function of the various indicators of irreversible degenerative changes, namely called Aging. Japan has now entered an advanced age society. For nearly half a century, Japan has been in the process of preventing aging and constructing a social pension service system, there is a lot to learn and we should learn from the successful experience.

Prevention of aging and successful construction of social pension service system in japanese experience

The Japanese government has been implementing the program of advancing the health and well-being of the elderly for 15 years from 1989 to 2004, also known as the "golden plan", in 1994-1999 it was called "new golden plan", in 1999-2004 it was called "golden plan 21 ". The series of "golden plans" has combined closely with the actual situation of Japan's economic and social development as well as its demographic characteristics. The successive introduction of the plans has promoted the sustainabledevelopmentofJapan'spensioncause, for the National Social Old-age Service System to achieve a virtuous cycle of solid foundation. 
The basic idea and starting point of Japan's implementation of the golden plan is to strive to ensure that all Japanese people has been enjoyed a peaceful old age. As a result, the government has expended considerable human, material and financial resources to substantially improve the quality of hardware facilities and services in the home and related social care institutions for the elderly, with a view to providing the necessary home, community and social support services for the elderly. Although each of the three golden projects has its own emphasis, it is necessary to improve the natural and social environment of community home care for the elderly and to enhance the comprehensive capacity of social institutions for the elderly, has always been the core objective and value of the Japanese government to improve the old-age policy, and throughout .The old-age security system in Japan has experienced four stages: free medical insurance benefits, separation of nursing service and medical insurance, integration of independent nursing insurance system and medical resources. the final phase of the intermediary insurance system attaches great importance to the elderly in the fields of medical care, coordinated care for the elderly and intermediary care services. The Japanese pension industry is different from the traditional medical industry and basically presents a situation of combining medical care with nursing care, the old-age service will be placed in the core position, radiating from the center to the surrounding, and finally become a diversified and multi-level integrated service industry integrating medical care, life care and so on.

Prevention first: Scientific exploration of the causes of disability and semi-disability

Among the difficulties and challenges of ageing, the most difficult challenge is the care of disabled and semi-disabled older persons. Because of the two main causes of long-term "bedridden" and "senile dementia", the Japanese government has emphasized prevention as the top priority and given a large policy-level tilt. This is one of the most successful aspects of Japan's social pension system. Emphasis on prevention, They can not wait until the body of the elderly really appear a variety of problems to solve, otherwise the elderly can miss the best time for prevention and treatment, as it is Chinese Medicine "cure no disease" conception. The main work of the Japanese government pension service is to spread the conception and knowledge of aging prevention to the whole society, and more importantly, to apply the scientific research results of aging prevention to the practice of providing for the elderly at home. Many civil society organizations and sports associations for the elderly in Japan spare no effort to promote and guide the scientific fitness of the elderly, and to prevent and treat diseases of the elderly through scientific, rational and regular physical exercise, enabling more older persons to get rid of various chronic diseases, promoting their physical and mental health, improving their ability to participate in social affairs, and actively participating in paid social activities, thus increasing the economic income of their families, it also improves the quality of life of the elderly and relieves the pressure of family and society.

Professionalized management: Improving the number and quality of specialized personnel in the provision of old-age services

An important success experiences of Japan's home-based Nursing Service in Japan

regardless of the establishment of the institution or the provision of the service personnel, all carry out unified and specialized training and management. First of all, Japan has special administrative agencies for the welfare of the elderly from the central to the local level, and has set up supporting agencies to supervise and balance government administrative agencies, it is also necessary to promote and educate the elderly to have a sense of self-management and confidence, and to vigorously develop the self-management organizations of the elderly, which are necessary conditions for the development of home-based old-age care services. Secondly, the Japanese staff engaged in elderly care services, need to go through professional training, examinations, to obtain qualifications before engaging in elderly care services. However, at present, the personnel engaged in home-based old-age care services in China lack professional knowledge in such areas as aging, nursing and rehabilitation, and can not effectively take care of the elderly, in particular, the daily life and rehabilitation of the disabled and semi-disabled elderly. In the future, more efforts should be made to train professionals to provide for the aged at home, and systematic training should be given to the existing staff who are engaged in providing for the elderly at home, which can not only relieve the stress of nurses, but also give full play to human resources. China has the largest and fastest-growing elderly population in the world. But China's social old-age security system is not yet sound. In the past ten years, the relevant departments of the state have successively introduced the relevant policies of the system of providing for the aged at home, which has also promoted the comprehensive development of community and social services for the aged.

\section{Conclusion}

"A stone from another mountain can attack jade.".In the process of constructing the social old-age service system in China, we can learn the advanced ideas and effective experience from Japan. Therefore, we need to focus on the implementation of preventive interventions that truly place people at the centre and enable everyone in every society to live a life of dignity in old age, leading to an active, healthy and graceful ageing. in the process of promoting the social old-age service guarantee system, such as the aging prevention, the old-age sports rehabilitation, the home-based old-age care system, and so on, there are many theoretical bases and practical experience which are worth learning and using for references by our country, in particular, the advanced scientific conception of prevention of aging and the specific training methods of rehabilitation activities for the elderly are accelerating the pace of aging in our country, and the number of disabled, semi-disabled and over-aged people is increasing rapidly, under the realistic background that the social old-age security system is not perfect, it is particularly important to study the advanced experience of developed countries.

\section{References}

1. Yuping G. Nursing Insurance System: A new initiative for Japanese pension security. Journal of the University of Anyang. 2004;2004(3):801.

2. Kongoe. Japan's Golden Plan and its main achievements. Scientific Socialism. 2014;2014(1) : 149.

3. Yuling Z. Research on the aging problem in the context of Harmonious Society. Zhejiang University Press. HANGZHOU: 2011:14-15

4. Songdong Y. Preliminary conception of establishing the Elderly Care System in China. Decision Consulting Newsletter. 2008; 2008 (03):90-91.

5. Peng D. Population Ageing and ageing. China Population Publishing House. Beijing: 2006:27.

6. Linhai C. Prevention, rehabilitation and home care for the aged: The successful experience and Enlightenment of Social Care Service System in Japan. Shanghai: Shanghai Science and Technology Education Press, 2012:7.

7. Kongoe. Japan's Golden Plan and its main achievements. 
Scientific Socialis. 2014; 2014:149.

8. Yasuyoshi. Japan's Golden Plan and its main achievements. Scientific Socialism 2014; 2014:150.

9. Zhou C, Weng J, Zhang B. Japanese mode of combining medical care with old-age care and its enlightenment to China. Medicine and philosophy. 2018;39(12):33-36.

10. Chen N, Wang C-q. The enlightenment of Japan's introduction insurance system on the improvement of China's disabled elderly care system. China Health Administration. 2019;36(2):104107,142 .

11. Zhou Z, Li H, Jia Y. The enlightenment of Japanese pension industry to the construction of medical-assisted pension model in China. China Health Administration. 2021;38(2):85-86.

12. Zhang X. Welfare policy for the Elderly In Japan and its enlightenment to us. Urban Issues. 2001; 2001(2):58.

13. Sun KN, Wang H. A study on the development of China's longterm Care Industry for the elderly. Journal of Social Sciences, Hunan Normal University. 2012; 2012(2):5-8.

14. Peng L. Enlightenment of Japanese Pension and welfare system and service facilities operation. Hubei Social Sciences. 2011;2011(8):61. 